\title{
Clinical Reasoning: An 81-year-old woman with decreased consciousness and fluctuating right facial droop
}

Randy Van Ommeren, MD, Aaron Izenberg, MD, FRCPC, Steven Shadowitz, MD, FRCPC, Richard Aviv, MD, FRCPC, and Julia Keith, MD, FRCPC

Neurology ${ }^{\circledR}$ 2020;94:843-848. doi:10.1212/WNL.0000000000009410
Correspondence

Dr. Keith

Julia.Keith@sunnybrook.ca

\section{Section 1}

An 81-year-old woman presented to the hospital after a week of intermittent episodes of decreased level of consciousness, right facial droop, and slurred speech, lasting approximately 30 minutes. Her medical history included chronic obstructive pulmonary disease, dyslipidemia, orthostatic hypotension, and 2 previous TIAs. She had fallen once in the preceding week, presumably as a result of her drowsiness. On examination, she was afebrile with a heart rate of 81 bpm and a blood pressure of $108 / 65 \mathrm{~mm} \mathrm{Hg}$. She was alert and cooperative, but disoriented to the year and location. Language examination was normal. Cranial nerves, motor, coordination, and sensory examinations were all normal without any focal deficits. However, when assessed during one of her episodes, she was less responsive, had decreased verbal output, and was noted to have a right facial droop. Basic serologic tests (complete blood count, electrolytes, renal function tests) were unremarkable. A head CT showed bilateral subarachnoid hemorrhage over the cerebral hemispheres without further abnormality.

\section{Questions for consideration:}

1. What is your differential diagnosis?

2. Which investigations would you perform at this point?

GO TO SECTION 2

From the Department of Laboratory Medicine and Pathobiology (R.V.O., J.K.) and Department of Medicine (S.S.), Division of Neurology (A.I.), Department of Radiology (R.A.), and Department of Laboratory Medicine and Molecular Diagnostics (J.K.), Sunnybrook Health Sciences Centre, University of Toronto, Canada.

Go to Neurology.org/N for full disclosures. Funding information and disclosures deemed relevant by the authors, if any, are provided at the end of the article. 


\section{Section 2}

The differential diagnosis for a patient with this presentation is broad. Categories that should be considered include meningitis, viral encephalitis, other infectious etiologies, toxic or metabolic encephalopathies, seizure disorders, cerebrovascular events, conditions causing increased intracranial pressure, and neuroinflammatory/autoimmune disorders, amongst others.

An MRI scan demonstrated extensive white matter T2 fluidattenuated inversion recovery signal abnormality asymmetrically affecting the left occipital and bilateral frontal lobes (figure).

Figure Radiologic and pathologic findings

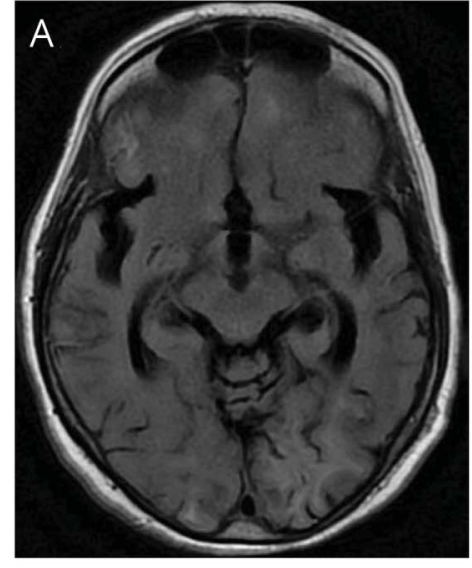

D
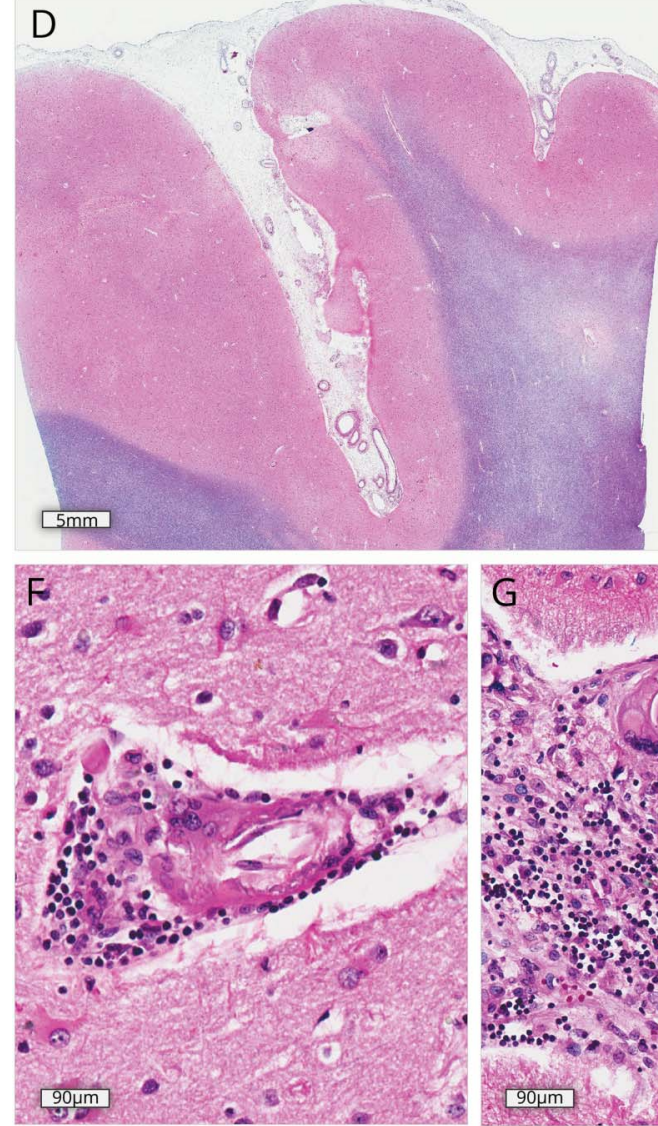
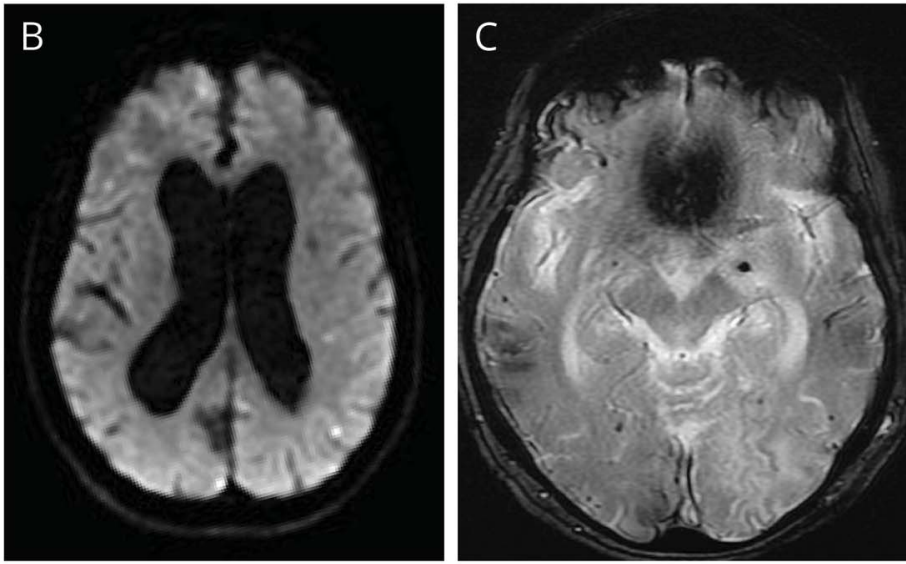

E. CD163
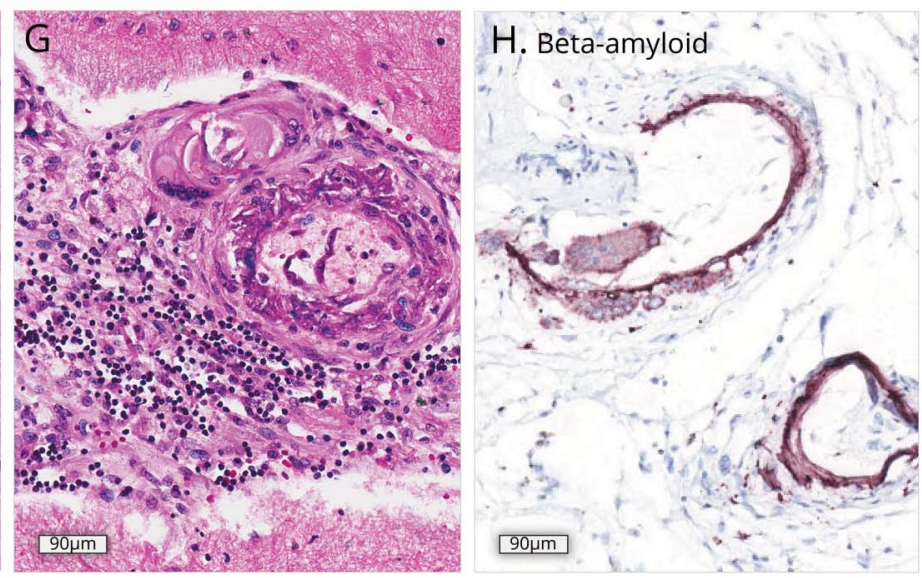

Fluid-attenuated inversion recovery (FLAIR) (A), diffusion-weighted imaging (DWI) (B), and multiplanar gradient recalled (MPGR) (C) axial images demonstrate widespread asymmetric T2 FLAIR hyperintensities with right frontal and left occipital predilection. Signal abnormality extends predominantly to the subcortical white matter with questionable regions of cortical involvement suspected within the right frontal and left occipital lobes. Several foci of diffusion restriction are evident within the bilateral frontal, left parietal, and right occipital lobes consistent with microinfarcts within multiple vascular territories. Gradient imaging demonstrates multiple regions of cortical superficial siderosis and microhemorrhages. Hematoxylin \& eosin (H\&E)/Luxol fast blue stain of the left frontal cortex (D) shows microinfarcts in both the cortex and underlying white matter, with patchy infiltration of macrophages into these regions demonstrated on a CD163 immunostain (E). High-power H\&E view of intraparenchymal (F) and leptomeningeal (G) vessels shows deposition of amorphous, eosinophilic material throughout the vessel wall layers. The vessels are round, with thickened and abnormal wall architecture, and fibrinoid necrosis. Prominent reactive surrounding gliosis is also appreciated. (H) Immunostaining of a frontal cortical section with amyloid- $\beta$ antibody confirms vascular amyloid deposition and vessel wall disruption. 
Multiple punctate foci of diffusion restriction consistent with acute infarction were evident on diffusion-weighted imaging within subcortical white matter and widespread within the supratentorial cortex and peripheral cerebellar hemispheres (figure). Susceptibility-weighted imaging using multiplanar gradient recalled acquisition sequences demonstrated multiple regions of microhemorrhages and cortical superficial siderosis (figure). A lumbar puncture was performed, which showed an elevated protein level $(623 \mathrm{mg} / \mathrm{L})$, mild leukocytosis (47 cells/ $\mu \mathrm{L}$ ), and negative cytology, cultures, and serology for cryptococcus; testing for antibodies against N-methyl-D-aspartate receptor, $\alpha$-amino-3-hydroxy-5-methyl-4-isoxazolepropionic acid receptor, and voltage-gated potassium channel in the CSF was negative. On serologic studies, C-reactive protein was slightly elevated $(58 \mathrm{mg} / \mathrm{mL})$; erythrocyte sedimentation rate (ESR) was normal $(50 \mathrm{mg} / \mathrm{mL})$; antinuclear antibody (ANA), antineutrophil cytoplasmic antibodies (ANCA), and extractable nuclear antigen were negative; and serology for West Nile virus and syphilis were negative. EEG testing showed a "focal polymorphism possibly indicative of recent seizure activity."

\section{Question for consideration:}

1. How would you refine your differential diagnosis based on these results?

GO TO SECTION 3 


\section{Section 3}

The MRI finding of leptomeningeal enhancement in combination with multiple foci of hemorrhage and superficial siderosis provide significant direction as to the etiology of this patient's symptoms. Differential diagnoses for diffuse leptomeningeal enhancement include infection (fungal, mycobacterial), neoplasm (melanocytosis, carcinomatosis, lymphomatosis), and inflammation (sarcoidosis, inflammatory amyloid angiopathy).

The elevated CSF protein without increased red blood cells, in the context of known hemorrhage and siderosis on imaging, points to a subacute or chronic pattern of bleeding. Negative
CSF cytology and culture reduce the likelihood of a neoplastic or infectious etiology. In this case, the pattern of asymmetric white matter hyperintensity and hemorrhage with superficial siderosis in a patient with elevated CSF protein and altered level of consciousness suggested a possible diagnosis of inflammatory amyloid angiopathy such as cerebral amyloid angiopathy (CAA)-related inflammation or $\beta$-amyloid $(\mathrm{A} \beta$ ) related angiitis (ABRA).

\section{Questions for consideration:}

1. What would be your management for this patient?

2. What are the histopathologic features of CAA and ABRA?

GO TO SECTION 4 


\section{Section 4}

The history and radiologic findings are highly suggestive of a diagnosis of inflammatory amyloid angiopathy. At admission, this patient was treated with phenytoin and then levetiracetam for suspected seizure activity. Her mental status continued to fluctuate, and she developed recurrent episodes of aspiration pneumonia. Pulsed steroids were initiated for a suspected diagnosis of inflammatory amyloid angiopathy. Her clinical condition did not improve and a repeat MRI showed worsening T2 hyperintense parenchymal edema with scattered acute infarcts. She eventually sustained a final aspiration event, went into hemodynamic shock, developed multiorgan failure, and died in the intensive care unit.

Definitive diagnosis of ABRA requires neuropathologic examination, either by brain biopsy or autopsy. Consent for postmortem examination was obtained. At macroscopic postmortem examination, the brain was swollen, showed significant leptomeningeal opacification, and several cerebral infarcts were seen. Microscopically, numerous subacute and remote microinfarcts were identified throughout the cortex and underlying white matter (figure) with variable infiltration of CD163 immunopositive macrophages (figure). There was extensive granulomatous inflammation and fibrinoid necrosis within vessels of the superficial brain parenchyma (figure) and leptomeninges (figure) with numerous multinucleated giant cells and associated gliosis. $A \beta$ immunohistochemistry confirmed amyloid deposition in the affected vessels (figure), with the additional finding of amyloid within activated microglia in adjacent parenchyma. Collectively, these findings permitted a definitive diagnosis of ABRA.

\section{Discussion}

CAA with perivascular inflammation or granulomatous (giant cell) angiitis has been described in the literature spanning the last 4 decades. These cases have different clinical and pathologic presentations than primary angiitis of the CNS or CAA alone, which lack findings of amyloid deposition and inflammation, respectively. Concurrent findings of CAA and perivascular inflammation have been designated as CAArelated inflammation (CAA-RI); when frank vessel wall inflammation with fibrinoid necrosis is present (as in our case), the term ABRA is used. ${ }^{1,2}$

The average age at CAA-RI and ABRA onset is $>50$ years, which is older than in primary angiitis of the CNS but younger than in CAA. ${ }^{3,4}$ The clinical presentation varies significantly between patients, but generally includes some combination of subacute cognitive or functional decline over a period of several months, new onset of seizure-like episodes, recurring or persistent headaches, perceptual disturbances such as hallucinations, or neurologic deficits such as visual disturbance or hemiparesis. ${ }^{1,3,5}$ Similar to patients with noninflammatory CAA, lobar hemorrhages caused by vessel wall rupture can result in a more acute clinical presentation. ${ }^{6}$ Imaging and biochemical testing of patients suspected to have ABRA is critical for timely and accurate diagnosis of this entity. In general, serum testing for ANA and ANCA is negative, and the ESR is normal in most patients (though elevated in some). CSF analysis frequently shows protein elevations $>70 \mathrm{mg} / \mathrm{dL}$, and a lymphocytepredominant leukocytosis well above 10 cells $/ \mathrm{mm}^{3}$. $^{3,5-7}$ Of note, the $A P O E \varepsilon 4 / \varepsilon 4$ genotype is enriched in patients with inflammatory angiopathy relative to noninflammatory CAA, suggesting a role for genetic (and downstream immunologic) contributions in the initiation or maintenance of the disease. $^{6}$

Careful radiopathologic correlation studies by several groups in recent years have delineated clinical and imaging features proposed to serve as a surrogate to invasive brain biopsy. ${ }^{8}$ Recently, clinicoradiologic criteria for a diagnosis of probable CAA-RI have been published, though the extent to which these apply to ABRA requires further validation. ${ }^{8}$ These criteria include (1) age over 40 years; (2) presence of one of headache, decreased consciousness, behavioral change, focal neurologic signs, or seizures; (3) unifocal or multifocal white matter hyperintensity (WMH) that is asymmetric and extends to the immediately subcortical white matter; (4) presence of one or more of cortical or subcortical hemorrhage, cerebral macrobleed or microbleed, or superficial siderosis; and (5) exclusion of other causes. In a validation cohort of 17 patients with pathologically confirmed CAA-RI, these criteria had a sensitivity and specificity of $82 \%$ and $97 \%$, respectively. ${ }^{8}$ Similar criteria for a diagnosis of possible CAA-RI, which broadened the permissible range of WMH, did not improve sensitivity, and reduced specificity significantly ( $82 \%$ and $68 \%$, respectively). ${ }^{8}$

The radiologic and clinical features of ABRA have been shown to be more responsive to immunosuppressive therapy than those of CAA, though a subset of patients have been shown to relapse and consequently show a poor prognosis. ${ }^{5,9}$ The primary treatment modality described in the literature is corticosteroid therapy, usually consisting of a course of oral prednisone or IV methylprednisolone pulse therapy. The use of other agents such as cyclophosphamide, methotrexate, azathioprine, mycophenolate mofetil, and IV immunoglobulin has also been described. ${ }^{4,7}$ Many patients show complete or near complete resolution of symptoms within a few weeks or months, though in a subset of patients $(\sim 18 \%$ in one published study) symptoms will relapse after discontinuation of therapy. ${ }^{1}$ In some cases, these patients will respond well to a second iteration of immunosuppressive therapy. ${ }^{5,7}$ Treatment is generally well-tolerated, though patients should be monitored for the side effects of short-term, high-dose corticosteroid therapy (such as hyperglycemia or psychosis). The lack of standardized therapeutic regimens and paucity of specific clinical, biochemical, or radiologic biomarkers predictive of prognosis mean that tailored approaches for agent or dose selection are not yet available. 
Neuropathologically, the findings in our case mirror those of other ABRA cases described in the literature, namely leptomeningeal and parenchymal inflammation around and within amyloid-laden blood vessels, comprising lymphocytes, macrophages, and giant cells (vasculitis). Both $A \beta_{40}$ and $A \beta_{42}$ isoforms are present, though the former is predominant. Vessels can show splitting, fibrinoid necrosis, and thrombosis, sometimes with recanalization. Finally, associated hemorrhage and parenchymal infarcts of varying ages are frequent findings. ${ }^{10}$ Together, these findings strongly suggest that the radiopathologic findings of ABRA are caused by immunologic response to $A \beta$ deposits in brain vasculature. This hypothesis is supported by in vivo experimental findings of severe vasculitis and vessel obliteration in an amyloid precursor protein transgenic mouse model, and by postmortem pathologic findings of severe meningoencephalitis in patients undergoing $A \beta$ vaccination for experimental treatment of Alzheimer disease. $^{5}$

\section{Consent}

The patient's family consented to postmortem examination for diagnostic and research purposes.

\section{Data availability}

All available data are provided within this article.

\section{Study funding}

No targeted funding reported.

\section{Disclosure}

R. Van Ommeren, A. Izenberg, S. Shadowitz, R. Aviv, and J. Keith report no relevant disclosures. Go to Neurology.org/N for full disclosures.

\begin{tabular}{lll} 
Appendix & Authors & \\
\hline Name & Location & Contribution \\
\hline $\begin{array}{l}\text { Randy Van } \\
\text { Ommeren, } \\
\text { MD }\end{array}$ & $\begin{array}{l}\text { University of } \\
\text { Toronto, } \\
\text { Canada }\end{array}$ & $\begin{array}{l}\text { Drafted manuscript body and } \\
\text { generated figure }\end{array}$ \\
\hline $\begin{array}{l}\text { Aaron } \\
\text { Izenberg, MD }\end{array}$ & $\begin{array}{l}\text { University of } \\
\text { Toronto, } \\
\text { Canada }\end{array}$ & $\begin{array}{l}\text { Assisted with drafting and review of } \\
\text { Clinical aspects of manuscript }\end{array}$ \\
\hline $\begin{array}{l}\text { Steven } \\
\text { Shadowitz, } \\
\text { MD }\end{array}$ & $\begin{array}{l}\text { University of } \\
\text { Toronto, } \\
\text { Canada }\end{array}$ & $\begin{array}{l}\text { Assisted with drafting and review of } \\
\text { clinical aspects of manuscript }\end{array}$ \\
\hline $\begin{array}{l}\text { Richard Aviv, } \\
\text { MD }\end{array}$ & $\begin{array}{l}\text { University of } \\
\text { Toronto, } \\
\text { Canada }\end{array}$ & $\begin{array}{l}\text { Assisted with drafting and review of } \\
\text { radiology aspects of manuscript }\end{array}$ \\
\hline $\begin{array}{l}\text { Julia Keith, } \\
\text { MD }\end{array}$ & $\begin{array}{l}\text { University of } \\
\text { Toronto, } \\
\text { Canada }\end{array}$ & $\begin{array}{l}\text { Supervised writing process, reviewed } \\
\text { all aspects of publication, including } \\
\text { pathologic descriptions }\end{array}$ \\
\hline
\end{tabular}

\section{References}

1. Salvarani C, Hunder GG, Morris J, Brown R, Christianson T, Giannini C. Amyloidbeta related angiitis: comparison with CAA without inflammation and primary CNS vasculitis. Neurology 2013;81:1596-1603.

2. Moussaddy A, Levy A, Strbian D, Sundararajan S, Berthelet F, Lanthier S. Inflammatory cerebral amyloid angiopathy, amyloid-beta-related angiitis, and primary angiitis of the central nervous system: similarities and differences. Stroke 2015;46:e210-213.

3. Scolding NJ, Joseph F, Kirby PA, et al. Abeta-related angiitis: primary angiitis of the central nervous system associated with cerebral amyloid angiopathy. Brain 2005;128:500-515.

4. Danve A, Grafe M, Deodhar A. Amyloid beta-related angitis: a case report and comprehensive review of literature of 94 cases. Semin Arthritis Rheum 2014;44:86-92.

5. Eng JA, Frosch MP, Choi K, Rebeck GW, Greenberg SM. Clinical manifestations of cerebral amyloid angiopathy-related inflammation. Ann Neurol 2004;55:250-256.

6. Kinnecom C, Lev MH, Wendell L, et al. Course of cerebral amyloid angiopathyrelated inflammation. Neurology 2007;68:1411-1416.

7. Salvarini CB RD, Calamia KT, Christianson TJH, et al. Primary central nervous system vasculitis: comparison of patients with and without cerebral amyloid angiopathy. Rheumatology 2008;47:1671-1677.

8. Auriel E, Charidimou A, Gurol ME, et al. Validation of clinicoradiological criteria for the diagnosis of cerebral amyloid angiopathy-related inflammation. JAMA Neurol 2016;73: 197-202.

9. Salvarani C, Brown RD Jr, Hunder GG. Adult primary central nervous system vasculitis. Lancet 2012;380:767-777.

10. Anders $\mathrm{KH}$, Wang ZZ, Kornfeld M, et al. Giant cell arteritis in association with cerebral amyloid angiopathy: immunohistochemical and molecular studies. Hum Pathol 1997;28:1237-1246.

\section{Call for Voices: Lived Experiences}

The Editors of the Neurology specialty site Equity, Diversity, \& Inclusion encourage you to submit short first-person accounts (1,000 words or less) of experiences lived within the realm of equity, diversity, and inclusion (EDI) with the goal of informing and enlightening our community on these critical issues. Some topics to consider include, but are not limited to:

- Descriptions of personal experiences that shaped your views of EDI.

- Reflections on the intersection between personal identity and career.

- Discussions at the intersection of EDI and neurology patient care, research, education, advocacy, or policy.

Submit your contributions to journal@neurology.org and include "Voices Submission" in the subject line. 


\section{Neurology}

\section{Clinical Reasoning: An 81-year-old woman with decreased consciousness and fluctuating right facial droop}

Randy Van Ommeren, Aaron Izenberg, Steven Shadowitz, et al.

Neurology 2020;94;843-848 Published Online before print April 21, 2020

DOI 10.1212/WNL.0000000000009410

\section{This information is current as of April 21, 2020}

\section{Updated Information \& Services}

References

Citations

Subspecialty Collections

Permissions \& Licensing

Reprints including high resolution figures, can be found at: http://n.neurology.org/content/94/19/843.full

This article cites 10 articles, 3 of which you can access for free at: http://n.neurology.org/content/94/19/843.full\#ref-list-1

This article has been cited by 1 HighWire-hosted articles: http://n.neurology.org/content/94/19/843.full\#\#otherarticles

This article, along with others on similar topics, appears in the following collection(s):

\section{Infarction}

http://n.neurology.org/cgi/collection/infarction

Intracerebral hemorrhage

http://n.neurology.org/cgi/collection/intracerebral_hemorrhage

Vascular dementia

http://n.neurology.org/cgi/collection/vascular_dementia

Vasculitis

http://n.neurology.org/cgi/collection/vasculitis

Information about reproducing this article in parts (figures,tables) or in its entirety can be found online at:

http://www.neurology.org/about/about_the_journal\#permissions

Information about ordering reprints can be found online:

http://n.neurology.org/subscribers/advertise

Neurology ${ }^{\circledR}$ is the official journal of the American Academy of Neurology. Published continuously since 1951, it is now a weekly with 48 issues per year. Copyright () 2020 American Academy of Neurology. All rights reserved. Print ISSN: 0028-3878. Online ISSN: 1526-632X.

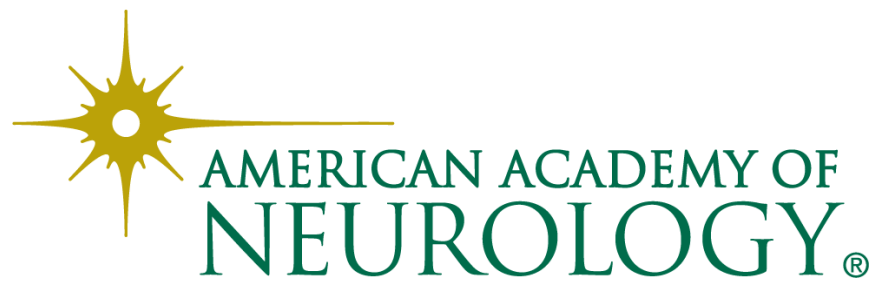

